\title{
END USER COMPUTING SATISFACTION ON WEBSITE PERPUSTAKAAN DAERAH SUMATERA SELATAN
}

\author{
Usman Ependi ${ }^{1)}$, Rusmin Syafari ${ }^{2)}$, dan Pitria Maharani ${ }^{3)}$ \\ ${ }^{1,2,3)}$ Fakultas Ilmu Komputer Universitas Bina Darma \\ JL A Yani No 3 Plaju Palembang \\ e-mail: $\underline{\text { u.ependi@ binadarma.ac.id }}{ }^{1)}$, rusmin.syafari@binadarma.ac.id $^{2)}$, pima@binadarma.ac.id ${ }^{3)}$
}

\begin{abstract}
ABSTRAK
Perpustakaan daerah (PUSDA) merupakan salah satu sarana yang disediakan oleh pemerintah daerah baik kabupaten maupun provinsi dalam upaya mencerdaskan kehidupan bangsa. Salah satu Pusda yang ada adalah Pusda Sumatera Selatan yang memiliki fasilitas website sebagai wajah Pusda dalam bentuk digital. Untuk memastikan bahwa fasilitas website yang disediakan telah sesuai dengan standar maka perlu untuk dilakukan pengukuran kepuasan pengguna. Pengukuran kepuasan dengan tujuan untuk mengetahui sejauh mana fasilitas website yang disediakan memberikan dampak terhadap pengguna. Sebagai instrument dalam pengukuran kepuasan menggunakn end user computing satisfaction (EUCS) yang telah terbukti sebagai alat ukur yang sistematis dan akurat. Dari hasil pengukuran yang dilakukan menunjukkan bahwa website Pusda Sumatera Selatan dapat dikategori baik, atau dengan kata lain pengguna merasa isi, keakuratan, bentuk, kemudahan, dan ketepatan waktu yang ada dapat memberikan kepuasan bagi pengguna.
\end{abstract}

Kata Kunci: EUCS, Pusda, Sumatera Selatan, Website.

\begin{abstract}
Regional library (Pusda) is one of the facilities provided by the local government both district and province in an effort to educate the nation. One of the existing Pusda is South Sumatra South Sumatra Pusda which has website facilities as the face of Pusda in digital form. To ensure that the website facilities provided are in accordance with the standards then it is necessary to measure user satisfaction. Measurement of satisfaction with the aim to know the impact given from the website to the user. As an instrument in measuring satisfaction using end user computing satisfaction (EUCS) which has been proven as a systematic and accurate measuring tool. From the results of measurements conducted indicate that the website Pusda South Sumatra can be categorized well, or can be conclude users feel the contents, accuracy, format, ease of use, and timeliness of existing can provide satisfaction for the user.
\end{abstract}

Keywords: EUCS, Library, South Sumatera, Website.

\section{Pendahuluan}

PESATNYA perkembangan teknologi informasi, telah mendorong terciptanya keterkaitan antar komputer dalam suatu jaringan internet. Salah satu sarana teknologi informasi melalui internet tersebut yaitu situs website (web), dimana pada web semua tersaji dengan cepat, mudah, efektif bahkan efisien. Semakin maraknya penggunaan informasi, telah membuat web menjadi suatu perhatian oleh banyak kalangan, mulai dari pemerintahan, praktisi media massa, perusahaan, hingga instansi akademik, salah satunya yang bergerak di bidang akademik yaitu perpustakaan. Perpustakaan menjadi sarana yang penting mengingat bahwa perpustakaan merupakan fasilitas belajar yang dibutukan terutama oleh para pelajar dan mahasiswa. Hal ini lah yang mendorong banyak perpustakaan telah didirikan, seperti di sekolah, di universitas, bahkan perpustakaan daerah yang menjadi perpustakaan utama yang ada dalam suatu daerah Provinsi, seperti Perpustakaan Daerah Sumatera Selatan.

Perpustakaan Daerah (PUSDA) merupakan badan daerah yang bergerak sebagai penyedia informasi media cetak belajar, referensi penelitian, dan kawasan edukasi. Sebagai kawasan edukasi, PUSDA terus melakukan peningkatan mutu pelayanan dan kinerja yang dapat dilihat dari sisi kemajuannya dalam memanfaatkan web yang sesuai dengan tujuannya untuk pengembangan teknologi, agar mempermudah proses kegiatan penyebaran, penerimaan, dan pembaruan informasi bagi para user atau pengunjungnya. Untuk mencapai itu semua dibutuhkan web yang memberikan tingkat kepuasan bagi para pengunjungnya. Masalah tingkat kepuasan pengunjung web ini penting, karena jika pengunjungnya merasa puas dalam menggunakan web tentu para pengunjung tersebut pun tertarik untuk terus menerus mengakses web PUSDA, dengan begitu dapat menaikkan jumlah pengunjung webnya dan meningkatkan kinerja ketergunaan web yang di bangun bagi para pengunjung PUSDA. Untuk mengetahui tingkat kepuasan tersebut, maka diperlukan analisa kepuasan pengunjung web badan perpustakaan daerah Sumatera Selatan. Untuk memperoleh hasil analisa yang dimaksud maka, dibutuhkan metode yang tepat untuk menganalisa yakni, dengan menggunakan metode EUCS. Metode ini yang memiliki lima komponen, yait $u$ content (isi), accuracy (keakuratan), format (bentuk), ease of use (kemudahan), dan timeliness (ketepatan waktu), komponen inilah yang akan menjadi tolak ukur pada web PUSDA. 


\section{Metodologi Penelitian}

Untuk menyajikan hasil penelitian yang akurat maka dalam penelitian ini digunakan metode metode sebagai alat bantu dalam proses penelitian. Metode metode tersebut dapat dijelaskan seabgai berikut:

\section{A. Metode Penelitian}

Penelitian ini adalah penelitian kuantitatif dengan metode eksplanasi (Korelasi). Penelitian eksplanasi adalah penelitian untuk menguji hubungan antar variable yang dihipotesiskan, ada hipotesis yang akan diuji kebenarannya [1]. Melalui penelitian tersebut, kita dapat melihat vaiasi hubungan antara variabel yang disebabkan oleh satu variable dengan variasi yang disebabkan oleh variable lain, entah itu variabel bebas ke variabel bebas, ataupun vaiabel bebas ke variabel terikat.

\section{B. Metode Pengumpulan Data}

Ada 2 jenis data yang digunakan dalam penelitian ini, yaitu data Primer dan data sekunder. Data primer dalah pengumpulan data yang dilakukan secara langsung pada lokasi penelitian dilakukan dengan cara metode angket (kuesioner), wawancara dan observasi. Namun dalam penelitian ini data primer yang digunakan berupa penyebaran kuesioner.

Pengumpulan data dengan kuesioner ini dilakukan pada bulan Desember 2016, selama 3 hari berturut-turut (14 - 16 Desember), dalam waktu 3 hari tersebut, peneliti membagikan kuesioner kepada para pengunjung PUSDA. Tiap lembar kuesioner yang dibagikan diterima oleh tiap responden yang berbeda pula, jika ada responden yang berkunjung dalam kurun waktu selama pembagian kuesioner, maka responden tersebut hanya mendapatkan 1 kali pengisian kuesioner saja. Sehingga tidak ada kuesioner ynag duplikat pengisiannya, jadi 100 kuesioner yang dibagikan diiisi oleh 100 responden pula dan data yang diterima memiliki 100 keragaman jawaban pula.

Selanjutnya data sekunder adalah kegiatan penelitian yang dilakukan dengan menelaah sejumlah buku, karya ilmiah, dan dokumen/arsip yang berhubungan dengan masalah yang diteliti [2]. Dalam penelitian ini data sekunder yang dilakukan berupa mencari referensi dalam jurnal, penelitian terdahulu, buku, dan materi di website.

\section{Populasi dan Sampel}

Populasi adalah semua bagian atau unit anggota dari objek yang akan diamati [1]. Berdasarkan penjelasan di atas, maka yang menjadi populasi dalam penelitian ini adalah seluruh anggota PUSDA, yang merupakan anggota PUSDA yang sedang berkunjung, anggota PUSDA berjumlah 33.817 anggota. dari sekian banyak jumlah pengunjung PUSDA yang setiap hari bisa berkisar 100 sampai 500 orang perhari, para anggota yang berkunjung sebanyak inilah yang termasuk dari dari populasi yang dimaksud dalam penelitian ini.

Selanjutnya tipe sampel yang digunakan merupakan probability sampling, dan sampel bersifat random (acak) dengan maksud sampel diambil secara acak, yang diberarti setiap anggota populasi yang memenuhi karakteristik dalam menjadi responden subjek penelitian, akan mempunyai kesempatan yang sama untuk dipilih menjadi anggota sampel namun para responden yang ada, dipilih secara acak dari jumlah populasi yang memenuhi kreteria yang ada. Sehingga jumlah populasi yang jumlahnya berkisar 100 samapi 500 yang ada, 100 orang diantaranya dalam kurun waktu 3 hari inilah yang secara acak terpilih menjadi responden untuk mengisi kuesioner yang ada, tanpa melihat dari jenis kelamin, urutan abjad nama, urutan nomer anggota, kuesioner yang ada disebar dan di terima secara acak oleh pengunjung yang ada.

Jumlah populasi adalah 33.817 (bagian pengolahan data PUSDA), mengingat jumlah yang begitu besar, maka banyaknya sampel dihitung dengan menggunakan (1) [3]:

$$
\mathrm{n}=\frac{N}{1+N e^{2}}
$$

Keterangan:

n: jumlah sampel

$\mathrm{N}$ : jumlah populasi

e: error tolerance/tingkat kesalahan yang ditoleransi.

Error tolerance adalah 10\%, maka jumlah sampel yang digunakan adalah:

$$
\mathrm{n}=\frac{33.817}{1+33.817 \cdot 10^{2}}=99,70 \approx 100
$$


Jadi, jumlah sampel berjumlah 100 orang, yang nantinya yang merupakan responden yang akan dituju dalam proses pengumpulan data merupakan anggota PUSDA, dengan batas usia 16 tahun, dan pernah membukan web PUSDA.

\section{Skala Pengukuran}

Skala yaitu proses pemberian nilai atau angka pada jawaban untuk memperoleh data kuantitatif yang diperlukan pada pengujian hipotesa dengan menggunakan teori Likert [4]. Skala memberikan penilaian dengan tingkatan angka yang sesuai dengan tingkat pengalaman dan penilaian menurut para responden seperti yang diperlihat pada Tabel I.

\begin{tabular}{cc} 
TABEL I & \\
SKALA PENILAIAN (LIKERT) & \\
\hline \hline Konteks & Nilai \\
\hline Sangat setuju & 5 \\
Setuju & 4 \\
Ragu-ragu & 3 \\
Tidak setuju & 2 \\
Sangat tidak setuju & 1 \\
\hline \hline
\end{tabular}

Data yang didapat dari jawaban responden yang diukur dengan menggunakan skala likert merupakan simbol dari data kualitatif untuk mewakili tingkat pengalaman responden dalam menggunakan web PUSDA dengan urutan angka seperti pada tabel 3.2, dimana skor yang ada merupakan tingkatan angka, sehingga mengukur tingkat kepuasaan responden, dengan begitu responden bisa langsung menyesuaikan angka yang tepat untuk mewakili pengalaman pengunjung dalam menggambarkan kepuasan penggunaan web.

\section{E. Hipotesis}

Sistem informasi suatu organisasi dapat diandalkan apabila memiliki kualitas yang baik dan mampu memberikan kepuasan pada pemakainya [5]. Maka dinyatakan dihipotesa diduga sebagai berikut:

1 Ho: Terdapat hubungan yang nyata/kuat dan positif antara variabel isi dan variabel kepuasan pengguna

Ha : Tidak terdapat hubungan yang nyata/kuat dan positif antara variabel isi dan variabel kepuasan pengguna

2 Ho: Terdapat hubungan yang nyata/kuat dan positif antara variabel akurat dan variabel kepuasan pengguna

Ha: Tidak terdapat hubungan yang nyata/kuat dan positif antara variabel akurat dan variabel kepua-

3 Ho : Terdapat hubungan yang nyata/kuat dan positif antara variabel bentuk dan variabel kepuasan pengguna

Ha : Tidak terdapat hubungan yang nyata/kuat dan positif antara variabel bentuk dan variabel kepuasan pengguna

4 Ho : Terdapat hubungan yang nyata/kuat dan positif antara variabel kemudahan dan variabel kepuasan pengguna

Ha : $\quad$ Tidak terdapat hubungan yang nyata/kuat dan positif antara variabel kemudahan dan variabel kepuasan pengguna

5 Ho : Terdapat hubungan yang nyata/kuat dan positif antara variabel ketepatan waktu dan variabel kepuasan pengguna

Ha : Tidak terdapat hubungan yang nyata/kuat dan positif antara variabel ketepatan waktu dan variabel kepuasan pengguna

6 Ho : Terdapat hubungan yang nyata/kuat dan positif antara variabel isi, akurat, bentuk, kemudahan dan ketepatan waktu dengan variabel kepuasan pengguna

7 Ha : Tidak Terdapat hubungan yang nyata/kuat dan positif antara variabel isi, akurat, bentuk, kemudahan, dan ketepatan waktu dengan variabel kepuasan pengguna

Dugaan inilah nantinya dapat dilihat setelah kuesioner disebar dan hasilnya diuji, untuk melihat apakah hipotesis awal atau hipotesis alternatif yang hasilnya tepat. 


\section{HASIL DAN PEMBAHASAN}

Dari proses penelitian yang telah dilakukan berdasarkan metodologi penelitian maka hasil yang diperoleh dapat dijelaskan seabgai berikut:

\section{A. Karateristik Responden}

Dalam melakukan penelitian terlebih dahulu, kita harus mengetahui karakteristik responden yang dituju, responden yang tuju merupakan anggota Perpustakaan Daerah Sumatera Selatan dengan batas minimal usia 16 tahun, supaya pertanyaan yang diajukan dapat dimengerti oleh responden, sehingga responden tersebut dapat mengisi pertanyaan sesuai dengan pengalaman dan pendapat responden dalam menggunakan web PUSDA, tapi penelitian ini tidak terpilah dari jenis kelamin, urutan abjad nama, dan urutan nomer keanggotaan PUSDA sehingga setiap anggota dengan usia 16 tahun keatas yang berkunjung ke PUSDA memiliki kesempatan yang sama untuk mengisi kuesioner yang dibagikan, pemilihan usia 16 tahun keatas ini supaya dapat mempermudah kegiatan pegisian kuesioner, karena diharapkan usia tersebut dapat mengerti rangkaian indikator dari pertanyaan kuesioner yang dibagikan.

Setiap responden yang telah mengisi kuesioner dihari pertama, maka dihari selanjutnya responden tersebut tidak dapat mengisi kuesioner lagi, supaya tiap kuesioner yang diisi oleh responden nilai memiliki integritas dan keragaman jawaban, dengan kata lain 100 kuesioner yang ada memiliki 100 responden pengisi jawaban pula. Jawaban responden tersebut telah dipastikan layak dijadilakn responden dengan melihat batasan usia minimal dan pernah membuka web PUSDA sehingga responden mempunyai pengalaman dalam menggunakan web yang diteliti ini. Sehingga sejumlah pertanyaan yang diajukan dalam variabel EUCS yang terdapat di kuesioner tersebut dapat memperoleh jawaban yang sesuai dalam tiap pengalam responden yang ada. Berikut ini merupakan karakteristik responden yang mengisi kuesioner berdasarkan persentase jenis kelamin, usia, dan pekerjaan.

1. Responden berdasarkan jenis kelamin: Laki-laki $42 \%$ dan Perempuan $48 \%$.

2. Responden berdasarkan persentase pekerjaan: Mahasiswa 89\%, PNS 2\%, Pengganguran 1\%, Pelajar 2\%, Guru 2\%, Wirausaha 2\% dan Karyawan Swasta $2 \%$.

3. Responden berdasarkan Persentase usia: usia 16 tahun - 20 tahun 55\%, usia 21 tahun -25 tahun 39\%, usia 26 tahun -30 tahun $4 \%$, usia 31 tahun -35 tahun $1 \%$, usia 36 tahun -40 tahun $0 \%$, usia 41 tahun 45 tahun $0 \%$, dan usia 46 tahun - 50 tahun $1 \%$.

\section{B. Indikator Variabel}

Sejumlah variabel EUCS (End User Computing Satisfaction) yang diteliti terdiri dari 5 variabel bebas dan 1 variabel terikat. Variabel terikat tersebut adalah content, accuracy, format, ease of use dan timeliness, dan variabel terikatnya adalah user satisfaction, untuk memudahkan langkah dalam melakukan pengujian data maka variabel yang ada didefinisikan sebagai berikut:

1. X1 (Content/ Isi) memiliki indikator berupa isi yang menarik untuk dilihat, jelas untuk dipahami, terus di update, dan keragaman informasi

2. $\mathrm{X} 2$ (Accuracy/ keakuratan) memiliki indikator berupa penyajiaan informasi akurat, memiliki integritas keutuhan data, hasil pencarian yang akurat, sesuai dengan hak akses user.

3. X3 (Format/ bentuk) memiliki indikator berupa bentuk tampilan web yang mudah untuk dikenali, menarik, perpaduan warna yang serasi, dan tata letak yang rapi.

4. X4 (Ease of use/ kemudahan) memiliki indikator berupa mudah mengunakan web, mencari informasi, mengambil informasi yang dibutuhkan, cara penggunaan konsisten, dan memiliki panduan penguna bagi pengguna awan.

5. X5 (Timeliness/ ketepatan waktu) memiliki indikator berupa cepat untuk mengakses web, response time, mendownload, hasil pencarian data, dan informasi yang uptodate.

6. Y (User Satisafction/ kepuasan pengunjung) memilki indikator berupa kepuasan dalam isi, keakuratan, bentuk, kemudahan, dan ketepatan waktu.

Indikator tersebutlah yang akan mengukur tingkat kepuasaan pengguna web PUSDA yang telah terkelompok dalam masing-masing variabel untuk nantinya dapat mengukur kepuasaan pengunjung webnya.

\section{Pengumpulan Data}

Selesai melakukan penelitian maka terkumpullah data yang didapat dari hasil penyebaran kuesioner, dalam penelitian ini data yang terkumpul berupa hasil jawaban para responden pada sejumlah indikator dalam masing masing variabel dalam EUCS, jawaban yang diberikan responden merupakan skor skala likert dari angka 1 sampai angka 5 yang mewakili tingkat kepuasan responden dalam pengalaman dan pendapat responden dalam menggunakan web PUSDA. Berikut ini merupakan hasil pengumpulan data yang didapat. 
TABEL II

HASIL PENGUMPULAN DATA (DATA PRIMER)

\begin{tabular}{|c|c|c|c|c|c|c|c|c|c|c|c|c|c|c|c|}
\hline \multirow[t]{2}{*}{ No } & \multirow{2}{*}{\multicolumn{2}{|c|}{ Variabel }} & \multicolumn{5}{|c|}{ Jawaban Responden } & \multirow[t]{2}{*}{ Total } & \multicolumn{5}{|c|}{ Persentase Jawaban } & \multirow[t]{2}{*}{ Nilai Butir } & \multirow[t]{2}{*}{ Nilai } \\
\hline & & & 1 & 2 & 3 & 4 & 5 & & 1 & 2 & 3 & 4 & 5 & & \\
\hline 1 & \multirow{4}{*}{$\mathrm{x} 1$} & $\mathrm{x} 1.1$ & 0 & 4 & 16 & 69 & 11 & 100 & $0 \%$ & $4 \%$ & $16 \%$ & $69 \%$ & $11 \%$ & 387 & \multirow{4}{*}{1465} \\
\hline 2 & & $\mathrm{x} 1.2$ & 0 & 2 & 20 & 66 & 12 & 100 & $0 \%$ & $2 \%$ & $20 \%$ & $66 \%$ & $12 \%$ & 388 & \\
\hline 3 & & $\mathrm{x} 1.3$ & 0 & 8 & 50 & 32 & 10 & 100 & $0 \%$ & $8 \%$ & $50 \%$ & $32 \%$ & $10 \%$ & 344 & \\
\hline 4 & & $\mathrm{x} 1.4$ & 0 & 15 & 34 & 41 & 10 & 100 & $0 \%$ & $15 \%$ & $34 \%$ & $41 \%$ & $10 \%$ & 346 & \\
\hline 5 & \multirow{5}{*}{$\mathrm{x} 2$} & $\mathrm{x} 2.1$ & 1 & 5 & 34 & 51 & 9 & 100 & $1 \%$ & $5 \%$ & $34 \%$ & $51 \%$ & $9 \%$ & 362 & \multirow{5}{*}{1760} \\
\hline 6 & & $\mathrm{x} 2.2$ & 0 & 4 & 40 & 50 & 6 & 100 & $0 \%$ & $4 \%$ & $40 \%$ & $50 \%$ & $6 \%$ & 358 & \\
\hline 7 & & $\mathrm{x} 2.3$ & 1 & 8 & 43 & 37 & 11 & 100 & $1 \%$ & $8 \%$ & $43 \%$ & $37 \%$ & $11 \%$ & 362 & \\
\hline 8 & & $\mathrm{x} 2.4$ & 0 & 5 & 36 & 52 & 7 & 100 & $0 \%$ & $5 \%$ & $36 \%$ & $52 \%$ & $7 \%$ & 361 & \\
\hline 9 & & $\mathrm{x} 2.5$ & 2 & 17 & 49 & 26 & 6 & 100 & $2 \%$ & $17 \%$ & $49 \%$ & $26 \%$ & $6 \%$ & 317 & \\
\hline 10 & \multirow{5}{*}{$\mathrm{x} 3$} & x 3.1 & 0 & 4 & 13 & 65 & 18 & 100 & $0 \%$ & $4 \%$ & $13 \%$ & $65 \%$ & $18 \%$ & 397 & \multirow{5}{*}{1829} \\
\hline 11 & & $\mathrm{x} 3.2$ & 0 & 9 & 17 & 67 & 7 & 100 & $0 \%$ & $9 \%$ & $17 \%$ & $67 \%$ & $7 \%$ & 372 & \\
\hline 12 & & x 3.3 & 0 & 11 & 28 & 54 & 7 & 100 & $0 \%$ & $11 \%$ & $28 \%$ & $54 \%$ & $7 \%$ & 357 & \\
\hline 13 & & x 3.4 & 1 & 8 & 32 & 52 & 7 & 100 & $1 \%$ & $8 \%$ & $32 \%$ & $52 \%$ & $7 \%$ & 356 & \\
\hline 14 & & x 3.5 & 0 & 10 & 41 & 41 & 8 & 100 & $0 \%$ & $10 \%$ & $41 \%$ & $41 \%$ & $8 \%$ & 347 & \\
\hline 15 & \multirow{5}{*}{$\mathrm{x} 4$} & $\mathrm{x} 4.1$ & 1 & 7 & 17 & 60 & 15 & 100 & $1 \%$ & $7 \%$ & $17 \%$ & $60 \%$ & $15 \%$ & 381 & \multirow{5}{*}{1818} \\
\hline 16 & & $\mathrm{x} 4.2$ & 0 & 8 & 18 & 60 & 14 & 100 & $0 \%$ & $8 \%$ & $18 \%$ & $60 \%$ & $14 \%$ & 380 & \\
\hline 17 & & $\mathrm{x} 4.3$ & 1 & 7 & 21 & 56 & 15 & 100 & $1 \%$ & $7 \%$ & $21 \%$ & $56 \%$ & $15 \%$ & 377 & \\
\hline 18 & & $\mathrm{x} 4.4$ & 0 & 2 & 47 & 44 & 7 & 100 & $0 \%$ & $2 \%$ & $47 \%$ & $44 \%$ & $7 \%$ & 356 & \\
\hline 19 & & $\mathrm{x} 4.5$ & 2 & 13 & 51 & 27 & 7 & 100 & $2 \%$ & $13 \%$ & $51 \%$ & $27 \%$ & $7 \%$ & 324 & \\
\hline 20 & \multirow{5}{*}{$\mathrm{x} 5$} & x5.1 & 1 & 9 & 26 & 53 & 11 & 100 & $1 \%$ & $9 \%$ & $26 \%$ & $53 \%$ & $11 \%$ & 364 & \multirow{5}{*}{1734} \\
\hline 21 & & x 5.2 & 1 & 8 & 49 & 35 & 7 & 100 & $1 \%$ & $8 \%$ & $49 \%$ & $35 \%$ & $7 \%$ & 364 & \\
\hline 22 & & $\mathrm{x} 5.3$ & 3 & 12 & 54 & 26 & 5 & 100 & $3 \%$ & $12 \%$ & $54 \%$ & $26 \%$ & $5 \%$ & 318 & \\
\hline 23 & & x 5.4 & 1 & 6 & 35 & 51 & 7 & 100 & $1 \%$ & $6 \%$ & $35 \%$ & $51 \%$ & $7 \%$ & 357 & \\
\hline 24 & & x 5.5 & 1 & 10 & 52 & 31 & 6 & 100 & $1 \%$ & $10 \%$ & $52 \%$ & $31 \%$ & $6 \%$ & 331 & \\
\hline 25 & \multirow{5}{*}{$\mathrm{Y}$} & y.x1 & 0 & 11 & 27 & 53 & 9 & 100 & $0 \%$ & $11 \%$ & $27 \%$ & $53 \%$ & $9 \%$ & 360 & \multirow{5}{*}{1751} \\
\hline 26 & & $y \cdot x 2$ & 0 & 10 & 49 & 34 & 7 & 100 & $0 \%$ & $10 \%$ & $49 \%$ & $34 \%$ & $7 \%$ & 338 & \\
\hline 27 & & y.x3 & 0 & 10 & 34 & 49 & 7 & 100 & $0 \%$ & $10 \%$ & $34 \%$ & $49 \%$ & $7 \%$ & 353 & \\
\hline 28 & & y.x4 & 2 & 6 & 38 & 48 & 6 & 100 & $2 \%$ & $6 \%$ & $38 \%$ & $48 \%$ & $6 \%$ & 350 & \\
\hline 29 & & y.x 5 & 0 & 8 & 39 & 48 & 5 & 100 & $0 \%$ & $8 \%$ & $39 \%$ & $48 \%$ & $5 \%$ & 350 & \\
\hline
\end{tabular}

Dari jawaban responden seperti yang ditampilkan pata Tabel II maka tiap indikator dari masing-masing variabel memiliki ragam jawaban tersendiri, karena diisi oleh tiap responden yang berbeda. Berikut masing-msing indikator yang dominan:

1. Variabel X1 yang memiliki nilai kepuasaan tertinggi pada indikator nomer dua, yang menanyakan tentang penyajian informasi yang menarik.

2. Variabel X2 yang memiliki nilai kepuasaan tertinggi pada indikator satu dan tiga, yang menanyakan tentang penyajian informasi yang akurat dan hasil pencarian data yang akurat.

3. Variabel X3 yang memiliki nilai kepuasaan tertinggi pada indikator satu, yang menanyakan tentang tampilan web ynag mudah dikenali.

4. Variabel X4 yang memiliki nilai kepuasaan tertinggi pada indikator satu, yang menanyakan tentang kemudahan dalam menggunakan web.

5. Variabel X5 yang memiliki nilai kepuasaan tertinggi pada indikator satu dan kedua, yang menanyakan tentang kecepatan dalam mengkases web dan kecepatan dalam respons time.

6. Variabel Y yang memiliki nilai kepuasaan tertinggi pada indikator satu, yang menanyakan tentang kepuasaan isi web.

7. Nilai kepuasaan tertinggi ada pada variabel X3 (format/bentuk) 


\section{Uji Validitas dan Reliabilitas}

Uji validitas dilakukan untuk mengetahui apakah alat ukur yang telah disusun benar-benar mengukur apa yang perlu diukur. Uji validitas berguna untuk menentukan seberapa cermat suatu alat melakukan fungsi ukurannya [6]. Alat ukur validitas yang tinggi berarti mempunyai varian kesalahan yang kecil, sehingga memberikan keyakinan bahwa data yang terkumpul merupakan data yang dapat dipercaya. Untuk melakukan pengujian validitas maka rumus yang digunakan seperi yang diperlihatkan pada (2).

$$
r_{\mathrm{xy}}=\frac{N \sum x y-\left(\sum x\right)\left(\sum y\right)}{\sqrt{N \sum x^{2}-\left(\sum \mathrm{x}\right)^{2}\left(N \sum y^{2}-\left(\sum \mathrm{y}\right)^{2)}\right.}}
$$

Keterangan:

$\mathrm{r}_{\mathrm{xy}}=$ koefisien Validitas

$\mathrm{N}$ = banyaknya subjek

$\mathrm{X}=$ nilai perbandingan

$\mathrm{Y}=$ nilai instrument yang akan dicari validitasnya.

Dasar pengambilan keputusan dalam uji validitas adalah:

Jika nilai $r_{\text {hitung }}>r_{\text {tabel, }}$, maka valid dan Jika nilai $r$ hitung $\leq r$ table maka tidak valid [3].

Seperti telah dijelaskan sebelumnya bahwa validitas menunjukan sejauh mana alat ukur dapat mengukur apa yang ingin diukur. Kuesioner yang peneliti gunakan sebagai alat ukur dalam penelitian ini diuji tingkat validitasnya dengan mengacu pada nilai $\mathrm{r}_{\text {tabel, }}$, dimana nilai kolerasi yang akan digunakan untuk mengukur validitas $(\mathrm{r}$ bt) harus positif atau lebih besar. Dalam penelitian ini $\mathrm{N}=100$, maka $\mathrm{r}$-tabel dan terdapat 6 variabel, $\mathrm{jd}$ df $=\mathrm{n}-$ $2=98$, dengan signifikansi 0,05 maka didapat $r$ tabel sebesar tingkat adalah 0.197 , hasil output pengujian validitas seperti ditunjukkan pada Tabel III

TABEL III

HASIL UJI VALIDITAS

\begin{tabular}{|c|c|c|c|c|c|c|c|c|}
\hline & & $\mathrm{x} 1$ & $\mathrm{x} 2$ & $\mathrm{x} 3$ & $\mathrm{x} 4$ & $\mathrm{x} 5$ & $\mathrm{y}$ & total \\
\hline $\mathrm{x} 1$ & Pearson Correlation & 1 &, $366^{* *}$ &, $331^{* *}$ &, $352^{* *}$ &, $376^{* *}$ &, $419^{* *}$ & $605^{* *}$ \\
\hline $\mathrm{x} 2$ & Pearson Correlation &, $366^{* *}$ & 1 &, $527^{* *}$ &, $565^{* *}$ &, $492^{* *}$ &, $517^{* *}$ &, $769^{* *}$ \\
\hline $\mathrm{x} 3$ & Pearson Correlation &, $331^{* *}$ &, $527^{* *}$ & 1 &, $632^{* *}$ &, $342^{* *}$ &, $507^{* *}$ &, $747^{* *}$ \\
\hline $\mathrm{x} 4$ & Pearson Correlation &, $352^{* *}$ &, $565^{* *}$ &, $632^{* *}$ & 1 &, $513^{* *}$ &, $571^{* *}$ &, $815^{* *}$ \\
\hline $\mathrm{x} 5$ & Pearson Correlation &, $376^{* *}$ &, $492^{* *}$ &, $342^{* *}$ &, $513^{* *}$ & 1 &, $549^{* *}$ &, $738^{* *}$ \\
\hline Y & Pearson Correlation &, $419^{* *}$ &, $517^{* *}$ &, $507^{* *}$ &, $571^{* * *}$ &, $549^{* *}$ & 1 &, $807^{* *}$ \\
\hline total & Pearson Correlation &, $605^{* *}$ &, $769^{* *}$ &, $747^{* *}$ &, $815^{* *}$ &, $738^{* *}$ &, $807^{* *}$ & 1 \\
\hline
\end{tabular}

**. Correlation is significant at the 0.01 level (2-tailed).

Dari hasil pengujian validitas seperti yang diperlihatkan pada Tabel III menunjukkan tiap komponen dari variabel yang ada memiliki kutipan ** setelah angka korelasinya. ** menggambarkan bahwa semua variabel yang ada memiliki validitas sebagai alat ukur yang digunakan dalam penelitian ini atau dapat dikatakan valid. Setelah dilakukan uji validitas atas pertanyaan atau pernyataan yang digunakan dalam penelitian ini, selanjutnya dilakukan uji reliabilitas. Uji reliabilitas bertujuan untuk mengetahui apakah alat pengumpul data pada dasarnya menunjukkan tingkat ketepatan, keakuratan, kestabilan atau konsistensi alat tersebut dalam mengungkapkan gejala tertentu dari sekelompok individu, walaupun dilakukan pada waktu yang berbeda. Uji keandalan dilakukan terhadap pertanyaan-pertanyaan atau pernyataan yang sudah valid. Pengujian ini dilakukan dengan menggunakan teknik Cronbach Alpha, karena nilai dari jawaban terdiri dari rentangan nilai dengan koefisien alpha harus lebih besar.

Koefisien alfa atau cronbach's alfha digunakan dalam penelitian ini untuk mengukur tingkat reliabilitas atau konsistensi interval diantara butir-butir pertanyaan dalam suatu instrument. Nilai reliabilitas konsistensi interval ditunjukan dalam tabel dibawah ini, untuk koefisien alfa masing-masing variabel dalam setiap variabel dan dinyatakan reliabel jika lebih besar dari 0,197. Dari tabel 4.3 telah disajikan data yang lebih memudahkan untuk melihat reliabiltas dari setiap varaiabel yang ada, dengan membandingkan niali bawah ini dapat cronbach's alpha dengan niali $\mathrm{r}_{\text {tabel }}$ dilihat bahwa kolerasi antara setiap item terdapat skor kolerasi yang tinggi, karena nilai $\mathrm{r}_{\text {tabel }}$ seperti yang diperlihatkan pada table 4 sampai dengan tabel 9. 
TABEL IV

HASIL UJI RELIABILITAS X1 - CONTENT

\begin{tabular}{ccc}
\hline \hline Cronbach's Alpha & Cronbach's Alpha Based on Standardized Items & N of Items \\
\hline 670 &, 667 & 4 \\
\hline \hline
\end{tabular}

Scale X1 $r_{\text {hitung }}>r_{\text {tabel }}(0,670>0,197)=$ reliabel, Dengan jumlah indikator dari content sebanyak 4 pertanyaan yang semuanya dinyatakan reliabel.

TABEL V

HASIL UJI RELIABILITAS X2 - ACCURACY

\begin{tabular}{ccc}
\hline \hline Cronbach's Alpha & Cronbach's Alpha Based on Standardized Items & N of Items \\
\hline \hline 6637 &, 647 & 5 \\
\hline \hline
\end{tabular}

Scale X2 $\mathrm{r}_{\text {hitung }}>\mathrm{r}_{\text {tabel }}(0,637>0,197)=$ reliabel, Dengan jumlah indikator dari accuracy sebanyak 5 pertanyaan yang semuanya dinyatakan reliabel.

TABEL VI

HASIL UJI RELIABILITAS X3 - FORMAT

\begin{tabular}{ccc}
\hline \hline Cronbach's Alpha & Cronbach's Alpha Based on Standardized Items & N of Items \\
\hline 731 &, 733 & 5 \\
\hline \hline
\end{tabular}

Scale X3 $\mathrm{r}_{\text {hitung }}>\mathrm{r}_{\text {tabel }}(0,731>0,197)=$ reliabel, Dengan jumlah indikator dari format sebanyak 5 pertanyaan yang semuanya dinyatakan reliabel.

TABEL VII

HASIL UJI RELIABILITAS X4 - EASE OF USE

\begin{tabular}{ccc}
\hline \hline Cronbach's Alpha & Cronbach's Alpha Based on Standardized Items & N of Items \\
\hline, 683 &, 678 & 5 \\
\hline \hline
\end{tabular}

Scale X4 $r_{\text {hitung }}>r_{\text {tabel }}(0,683>0,197)=$ reliabel, Dengan jumlah indikator dari ease of use sebanyak 5 pertanyaan yang semuanya dinyatakan reliabel.

TABEL VIII

HASIL UJI RELIABILITAS X5 - TIMELINES

\begin{tabular}{ccc}
\hline \hline Cronbach's Alpha & Cronbach's Alpha Based on Standardized Items & N of Items \\
\hline \multirow{2}{*}{, 727} &, 726 & 5 \\
\hline \hline
\end{tabular}

Scale X5 $r_{\text {hitung }}>r_{\text {tabel }}(0,727>0,197)=$ reliabel, Dengan jumlah indikator dari timeliness sebanyak 5 pertanyaan yang semuanya dinyatakan reliabel.

TABEL IX

HASIL UJI RELIABILITAS X5 - USER SATISFACTION

\begin{tabular}{ccc}
\hline \hline Cronbach's Alpha & Cronbach's Alpha Based on Standardized Items & N of Items \\
\hline, 803 &, 802 & 5 \\
\hline
\end{tabular}

Scale $\mathrm{Y} \mathrm{r}_{\text {hitung }}>\mathrm{r}_{\text {tabel }}(0,803>0,197)=$ reliabel, Dengan jumlah indikator dari user satisfaction sebanyak 5 pertanyaan yang semuanya dinyatakan reliabel.

Hasil pengujian seperti pada Table IV-IX menggambarkan bahwa semua variabel yang ada memiliki nilai reliabilitas untuk menunjukan bahwa alat pengumpul data memiliki tingkat ketepatan dan alat tersebut mampu mengungkapkan gejala tertentu dari sekelompok individu, walaupun dilakukan pada waktu yang berbeda. 


\section{E. Pengujian Hipotesis}

Pengujian hipotesis dilakukan dengan uji statistik dengan menggunakan metode Regresi Linier Berganda [7], karena variabel independen yang digunakan lebih dari satu variabel, Analisa Regresi Berganda digunakan untuk melihat pengaruh antara lebih dari satu variabel, yang dalam penelitian ini adalah isi X1 (Conten/ isi), X2 (Accuracy/ keakuratan), X3 (Format/ bentuk), X4 (Ease of Use/ kemudahan penggunaan) dan X5 (Timelines/ketepatan waktu) terhadap Y (User saatisfaction/ kepuasan pemakai) Untuk mengetahui dugaan yang ada, terhadap besar kecil variabel terikat. Untuk itu dilakukan uji $\mathrm{F}$ dan uji T. Uji $\mathrm{F}$ ini bertujuan untuk menguji apakah variabel EUCS secara bersama-sama mempunyai pengaruh yang signifikan terhadap kepuasan pemakai web PUSDA bagi penggunanya yang merupakan anggota PUSDA itu sendiri. Uji F ini dilakukan degan membandingkan F hitung yang dihitung dengan $\mathrm{F}$ tabel. Hasil uji F seperti yang diperlihatkan pada Tabel X.

\begin{tabular}{|c|c|c|c|c|c|c|}
\hline \multicolumn{7}{|c|}{$\begin{array}{c}\text { TABEL X } \\
\text { HASIL UJI F } \\
\text { ANOVA }^{\mathrm{b}}\end{array}$} \\
\hline & Model & Sum of Squares & Df & Mean Square & $\mathrm{F}$ & Sig. \\
\hline \multirow{3}{*}{1} & Regression & 387,940 & 5 & 77,588 & 16,999 &, $000^{\mathrm{a}}$ \\
\hline & Residual & 429,050 & 94 & 4,564 & & \\
\hline & Total & 816,990 & 99 & & & \\
\hline
\end{tabular}

a. Predictors: (Constant), x5, x3, x1, x2, x4

b. Dependent Variable: $y$

Untuk mengetahui tingkat signifikansi hubungan variable independent secara bersama-sama simultan terhadap variable dependen dilakukan dengan mengunakan uji $\mathrm{F}$ yaitu dengan cara membandingkan antara $\mathrm{F}$ hitung dengan $\mathrm{F}$ tabel. Dari hasil perhitungan statistic yang mengunakan SPSS 18 yang berarti, pengujian secara simul$\tan \mathrm{X} 1, \mathrm{X} 2, \mathrm{X} 3$ dan X4 terhadap $\mathrm{Y}$, dari tabel diperoleh nilai $\mathrm{F}_{\text {hitung }}$ sebesar 16, 999 dengan nilai probabilitas (sig) $=0,00$. Nilai $F_{\text {hitung }}(16,999)>F_{\text {tabel }}(2,47)$, dan nilai sign lebih kecil dari nilai probabilitas 0,05 atau nilai $0,00<$ 0,05 maka $\mathrm{H}_{0}$ diterima, berarti secara bersama-sama (simultan) X1, X2, X3, X4 dan X5 berhubungan signifikan atau nyata terhadap kepuasaan pengunjung web PUSDA. Setelah dilakukan uji $\mathrm{F}$ maka selanjutnya adalah melakukan uji T. uji T menunjukan seberapa besar jauh hubungan satu variable independent secara parsial dalam menerangkan variasi variable dependent, secara mandiri, antara X1 ke Y, X2 ke Y, X3 ke Y, X4 ke Y dan X5 ke Y. Hasil uji T ditunjukkan pada Tabel XI

\begin{tabular}{|c|c|c|c|c|c|c|}
\hline & \multicolumn{6}{|c|}{$\begin{array}{l}\text { TABEL XI } \\
\text { HASIL UJI T } \\
\text { Coefficient }^{\text {a }}\end{array}$} \\
\hline & \multirow{2}{*}{ Model } & \multicolumn{2}{|c|}{ Unstandardized Coefficients } & \multirow{2}{*}{$\begin{array}{c}\text { Standardized Coefficients } \\
\text { Beta }\end{array}$} & \multirow{2}{*}{$\mathrm{t}$} & \multirow{2}{*}{ Sig } \\
\hline & & $\mathrm{B}$ & Std. Error & & & \\
\hline \multirow{6}{*}{1} & (Constant) &,- 301 & 2,007 & &,- 150 &, 881 \\
\hline & $\mathrm{x} 1$ &, 195 &, 115 &, 142 & 1,699 &, 093 \\
\hline & $\mathrm{x} 2$ &, 149 &, 116 &, 127 & 1,289 & ,200 \\
\hline & $\mathrm{x} 3$ & ,190 &, 110 &, 173 & 1,718 & ,089 \\
\hline & $\mathrm{x} 4$ &, 220 &, 119 &, 200 & 1,845 & ,068 \\
\hline & $\mathrm{x} 5$ &, 284 &, 097 &, 271 & 2,929 &, 004 \\
\hline
\end{tabular}

a. Dependent Variable: y

Jika nilai sig pada tabel < nilai sign constanta $(0,05)$ maka Ha diterima dan H0 ditolak sehingga menunjukkan hubungan yang nyata, namun jika nilai sig pada tabel > nilai sign constanta $(0,05)$ maka H0 diterima dan Ha ditolak sehingga menunjukkan hubungan yang tidak nyata. Hal ini berarti bahwa tidak ada hubungan yang signifikan dari variabel Content secara parsial terhadap variabel kepuasan pemakai.

1. $\left(\mathrm{X}_{1}\right)$ terhadap $(\mathrm{Y})$, Terlihat pada tabel Coefficients model 1 terdapat nilai sig 0,93 . Nilai sig lebih besar dari nilai probabilitas 0,05 , atau nilai $0,93>0,05$, maka $\mathrm{H}_{0}$ diterima dan Ha ditolak, berarti terdapat hubungan yang nyata/kuat antara variabel isi dan variabel kepuasaan pengguna. Nilai t positif menunjukkan bahwa variabel $\mathrm{X}_{1}$ mempunyai hubungan yang searah dengan $\mathrm{Y}$.

2. $\left(\mathrm{X}_{2}\right)$ terhadap $(\mathrm{Y})$, Terlihat pada tabel Coefficients model 1 terdapat nilai sig 0,200. Nilai sig lebih besar dari nilai probabilitas 0,05 , atau nilai $0,200>0,05$, maka $\mathrm{H}_{0}$ diterima dan Ha ditolak, berarti terdapat hubungan yang nyata/kuat antara variabel keakuratan dan variabel kepuasaan pengguna. Nilai t positif menunjukkan bahwa $\mathrm{X}_{2}$ mempunyai hubungan yang searah dengan $\mathrm{Y}$. 
3. $\left(\mathrm{X}_{3}\right)$ terhadap (Y), Terlihat pada tabel Coefficients model 1 terdapat nilai sig 0,089. Nilai sig lebih besar dari nilai probabilitas 0,05 , atau nilai $0,089>0,05$, maka $\mathrm{H}_{0}$ diterima dan Ha ditolak, berarti terdapat hubungan yang nyata/kuat antara variabel bentuk dan variabel kepuasaan pengguna. Nilai t positif menunjukkan bahwa $\mathrm{X}_{3}$ mempunyai hubungan yang searah dengan $\mathrm{Y}$.

4. $\left(\mathrm{X}_{4}\right)$ terhadap $(\mathrm{Y})$, Terlihat pada tabel Coefficients model 1 terdapat nilai sig 0,068. Nilai sig lebih besar dari nilai probabilitas 0,05 , atau nilai $0,068>0,05$, maka $\mathrm{H}_{0}$ diterima dan Ha ditolak, berarti terdapat hubungan yang nyata/kuat antara variabel kemudahan dan variabel kepuasaan pengguna. Nilai t positif menunjukkan bahwa $\mathrm{X}_{4}$ mempunyai hubungan yang searah dengan $\mathrm{Y}$.

5. $\left(\mathrm{X}_{5}\right)$ terhadap $(\mathrm{Y})$, Terlihat pada kolom Coefficients model 1 terdapat nilai sig 0,004. Nilai sig lebih kecil dari nilai probabilitas 0,05, atau nilai $0,004<0,05$, maka Ha diterima dan $\mathrm{H} 0$ ditolak, berarti tidak terdapat hubungan yang nyata/kuat antara variabel ketepatan waktu dan variabel kepuasaan pengguna. Nilai t positif menunjukkan bahwa $\mathrm{X}_{5}$ mempunyai hubungan yang searah dengan $\mathrm{Y}$.

\section{F. Uji Normalitas}

Uji normalitas adalah untuk mengetahui apakah variabel terikat dan variable bebas keduanya mempunyai distribusi normal atau tidak. Cara untuk mendeteksi normalitas adalah dengan melihat penyebaran data (titik-titik) pada sumbu diagonal dari grafik [8]. Dasar pengambilan keputusan dalam uji normalitas adalah sebagai berikut:

1. Jika data menyebar disekitar garis diagonal dan mengikuti arah garis diagonal, maka memenuhi asumsi normalitas.

2. Jika data menyebarkan jauh dari garis diagonal dan tidak mengikuti arah garis diagonal, maka tidak memenuhi asumsi normalitas.

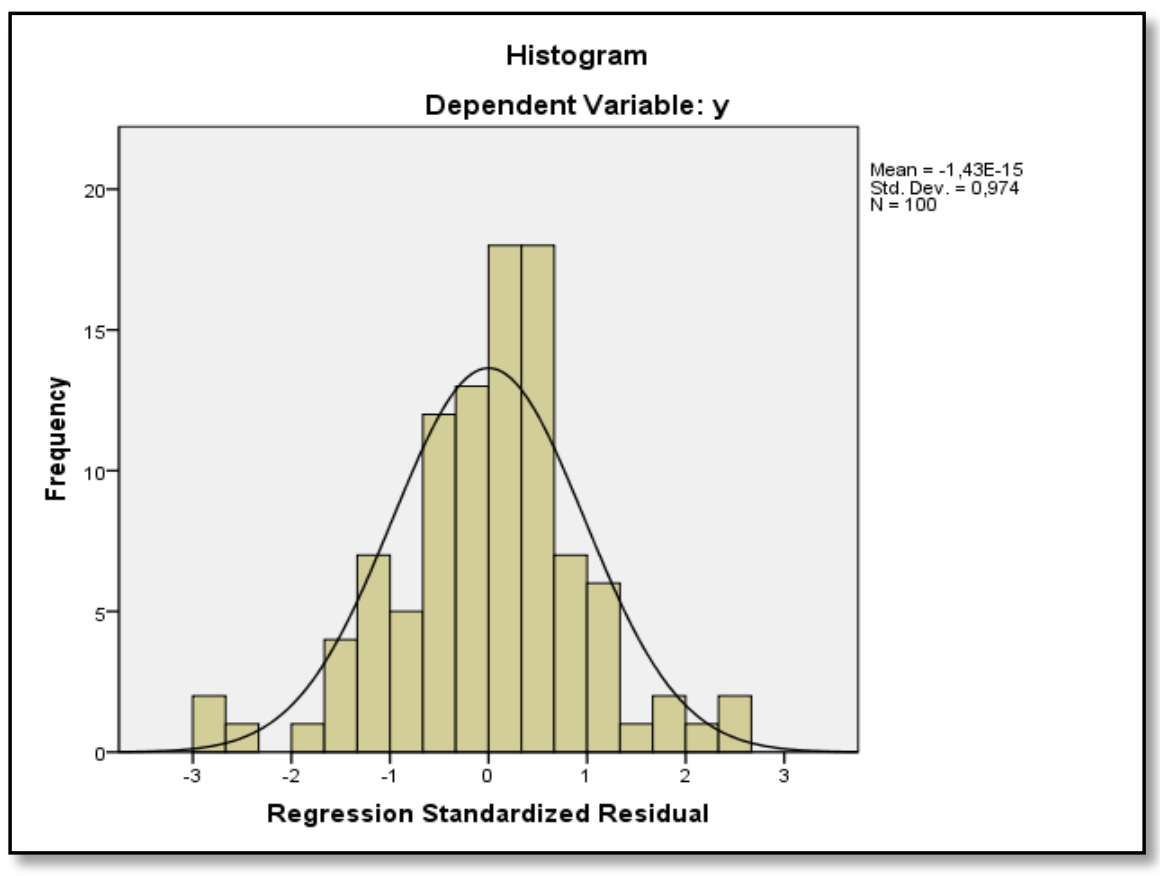

Gambar. 1. Hasil uji normalitas

Seperti yang diperlihatkan pada Gambar 1 menunjukkan bahwa histogram menyebar disekitar garis diagonal dan mengikuti arah garis diagonal, maka dapat disimpulkan bahwa pola distribusi yang ada wajar dan normal, sehingga jawaban yang diberikan oleh responden merupakan jawaban yang normal dan wajar dan tidak terdapat data residu.

Setelah melakukan uji normalitas maka selanjutnya adalah melakukan uji heterokedastisitas. Uji heterokedastisitas bertujuan untuk menguji apakah data terjadi ketidaksamaan varian dari suatu pengamatan ke penngamatan yang lain. Jika varian dari residual suatu pengamatan lain tetap, maka disebut heterokkedastis. Hasil Uji heterokedastisitas seperti yang diperlihatkan pada Gambar 2.

Data yang baik adalah bersifat homokedastis. Cara untuk mendeteksi ada atau tidaknya heterokedastis adalah melihat grafik plot dasar pengambilan keputusannya adalah sebagai berikut:

1. Jika ada pola tertentu, seperti titik-titik yang ada membentuk pola tertentu yang teratur (bergelombang, melebar kemudian menyempit), maka mengindikasikan telah terjadi heteroskedastisitas.

2. Jika tidak ada pola yang jelas, serta titik-titik menyebar diatas dan dibawah angka 0 pada sumbu Y, maka tidak terjadi heteroskedatisitas. 


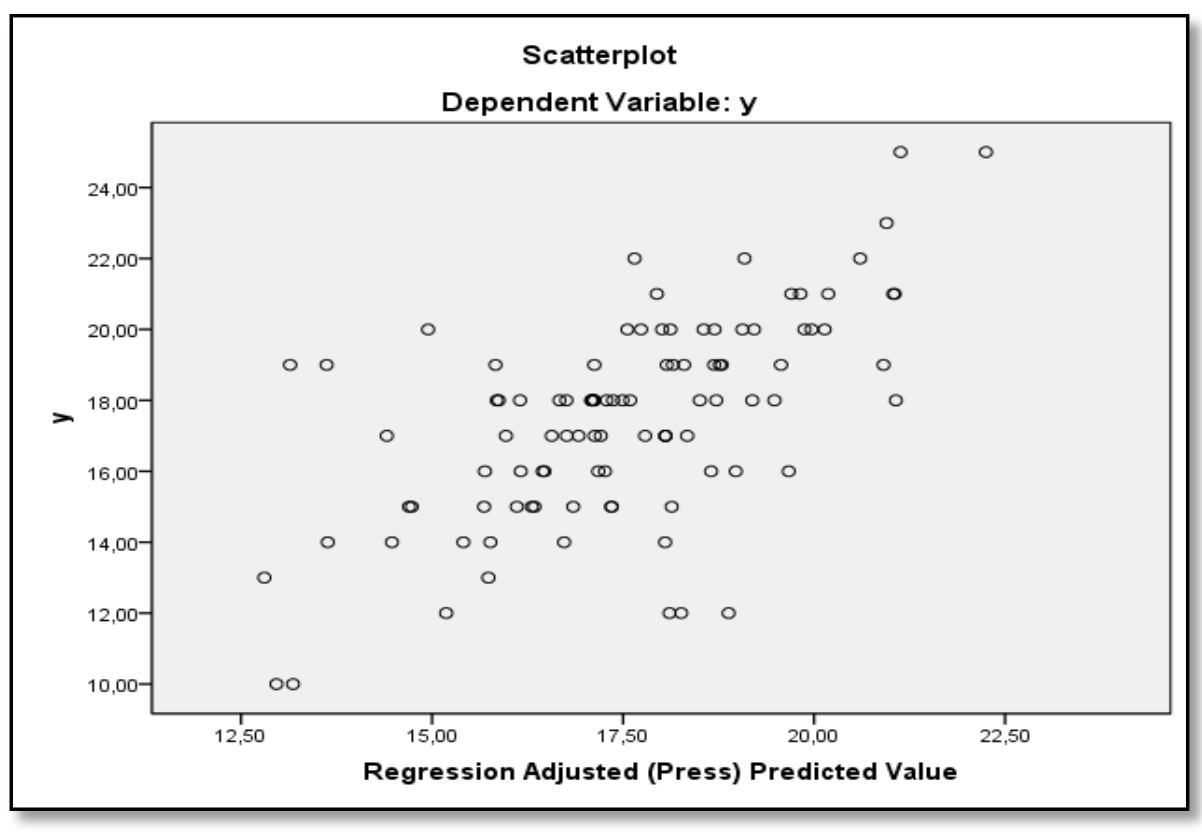

Gambar. 2. Penyebaran Heterokedastisitas

Sesuai dengan tampilan pada Gambar 2 maka dapat disimpulkan bahwa plot menunjukkan pola distribusi yang menyebar dan beraturan namun, ada beberapa posisi yang terjadi penumpukan, yang berarti ada beberapa jawaban responden yang sama pada beberapa indikator namun jawaban tersebut masih tergolong dalam karateristik heterokedastisitas.

\section{G. Pengujian Akhir}

Pengujian akhir merupakan cara untuk melihat seberapa besar variabel yang ada dalam penelitian memberikan nilai kepuasan, dimana variabel yang ada merupakan variabel yang terdapat dalam metode EUCS yang mengukur kepuasaan pengunjung, dan melihat variabel lain yang tidak termasuk dalam penelitian ini memberikan nilai kepuasan pengunjung. Hasil pengujian akhir ditunjukkan oleh Tabel XII.

TABEL XII

HASIL PENGUJIAN AKHIR

\begin{tabular}{|c|c|c|c|c|c|c|c|c|c|c|c|}
\hline \multirow{2}{*}{ Model } & & \multirow{2}{*}{$\mathrm{R}$} & \multirow{2}{*}{$\begin{array}{c}\mathrm{R} \\
\text { Square }\end{array}$} & \multirow{2}{*}{$\begin{array}{l}\text { Adjusted R } \\
\text { Square }\end{array}$} & \multirow{2}{*}{$\begin{array}{l}\text { Std. Error of } \\
\text { the Estimate }\end{array}$} & \multicolumn{5}{|c|}{ Change Statistics } & \multirow{2}{*}{$\begin{array}{l}\text { Durbin- } \\
\text { Watson }\end{array}$} \\
\hline & & & & & & $\begin{array}{l}\text { R Square } \\
\text { Change }\end{array}$ & $\begin{array}{c}\mathrm{F} \\
\text { Change }\end{array}$ & df1 & df 2 & $\begin{array}{c}\text { Sig. F } \\
\text { Change }\end{array}$ & \\
\hline dimension0 & 1 &, $689^{a}$ & ,475 & ,447 & 2,13644 & ,475 & 16,999 & 5 & 94 &, 000 & 1,494 \\
\hline
\end{tabular}

a. Predictors: (Constant), x5, x3, x1, x2, x4

b. Dependent Variable: $y$

Dari pengujian akhir seperti yang diperlihatkan pada Tabe 12 terdapat Angka R Square sebesar 0,475 dan angkat Adjusted R square sebesar 0, 447 menunjukkan bahwa 47,5\% variabel Kepuasan dapat dijelaskan oleh kelima variabel independent yang ada yaitu X1 (content), x2 (accuracy), x3 (format), x4 (easy of use), dan x5 (timeliness). Sedangkan sisanya sebesar 52,5\% dijelaskan oleh faktor dari variabel lain yang tidak terdapat dalam penelitian ini. Selain itu juga pada tabel 12 terdapat angka R sebesar 0, 689 yang menunjukan hubungan antara 5 variabel bebas tersebut (content, accuracy, format, ease of use dan timeliness) dengan variabel terikat (user satisfaction) adalah positif dan signikansi atau nyata.

\section{KESIMPULAN}

Kepuasaan web PUSDA dapat dikategorikan baik atau memberikan tingkat kepuasan kepada pengguna, Karena menurut perhitungan skor total yang diperoleh dari masing-masing variabel, didapatkan bobot nilai setuju sebesar $56,3 \%$, nilai ragu-ragu sebesar $34,8 \%$ dan nilai tidak setuju sebasar $8,79 \%$ yang mengartikan bahwa tanggapan yang diberikan oleh aggota adalah baik. Sehingga rata - rata jawaban responden dari setiap variabel adalah Setuju sebesar $73,7 \%$, dan jawaban yang tidak setuju sebesar $26,3 \%$ dengan melihat perbandingan yang cukup jauh antar skor yang ada dapat diartikan web PUSDA tersebut memberikan kepuasan bagi para pengunjungnya yang dilihat dari metode EUCS. Selain itu juga dari 5 variabel yang ada, variabel X3 (format/ bentuk) yang memiliki nilai kepuasaan tertinggi. 
Ependi, Syafari, dan Maharani — End Uer Computing Satisfaction on Website Perpustakaan Daerah Sumatera Selatan

\section{DAFTAR PUSTAKA}

[1] A. Elvinaro, "Metodologi Penelitian Untuk Public Relations Kuantitatif dan Kualitatif', Bandung, Indonesia, 2010, Simbiosa Rekatama Media, hal. 50

[2] A. Masrokan, dkk. "Marketing Knowledge Capacity And Marketing Performance Of Marketing (Study Case At Cv. Rajawali Mas Semarang)", Jurnal Orientation Effect Of Entrepreneurship. Vol 2 No 2, 2016, hal 4

[3] N. Wirastuti, dkk. "Tingkat Kepuasaan Pengguna Website www.unud.ac.id”. Jurnal SPEKTRUM Vol. 2, No 2, 2015, hal 129

[4] B. Kusdiana, dkk. "Pengembangan Karir Dan Kepuasan Kerja Terhadap Produktifitas Karyawan PT. AST Indonesia". Jurnal Pengaruh Iklim Organisasi Vol 2 No 2, 2016 hal 4-5

[5] T. D. R Yustanti. "Faktor-Faktor Yang Mempengaruhi Kepuasan Penggunaan E-Procurement Oleh Penyedia Barang Dan Jasa (Studi Kasus Di Pemerintah Kota Surakarta)". Jurnal EKA CIDA Vol 1 No 1, 2016, hal 5

[6] J. Noo. "Metodologi penelitian". Jakarta, Indonesia, 2011, Kencana

[7] Mardiyati, U., Ahmad, G.N. and Putri, R. "Pengaruh Kebijakan Dividen, Kebijakan Hutang dan Profitabilitas Terhadap Nilai Perusahaan Manufaktur yang Terdaftar di Bursa Efek Indonesia (BEI) Periode 2005-2010". JRMSI-Jurnal Riset Manajemen Sains Indonesia, Vol 3 No1, 2017, hal. 1-17.

[8] O. M. Arvira, dan H. B. Notobroto. "Perbandingan Tingkat Konsistensi Normalitas Distribusi Metode Kolmogorov-Smirnov, Lilliefors, Shapiro-Wilk, dan Skewness-Kurtosis" Jurnal Biometrika dan Kependudukan Volume 3 No. 2, 2014. hal. 127-135. 
JTIULM - Volume 03, Nomor 1, April 2018: 35 - 46 